\title{
Development of Design System for Building Fire Safety
}

\author{
T. WAKAMATSU
}

Department of Architecture

Faculty and Science and Technology

Science University of Tokyo

Yamazaki, Noda-City, Chiba-Pref., Japan

\author{
BRI Fire Research Group \\ Building Research Institute \\ Ministry of Construction \\ Tatehara 1, Tsukuba-City, Ibaraki-Pref., Japan
}

\section{ABSTRACT}

Development of performance fire safety code is one of the major objectives of current fire safety science. In order to provide a technical basis for a performance building code, Building Research Institute has organized a research program "Development of Design System for Building Fire Safety" during 1982-87. Brief introduction of its background, its structure, its relation with the present regulation and an example of the application of this system are given.

key words: fire safety design, performance standard, evaluation.

\section{INTRODUCTION}

Fire safety measures for buildings have been usually designed to meet specification standards in most of the industrialized countries. However, it is widely recognized that specification fire safety codes would sometimes lead to such difficulties as relatively low efficiency of fire safety measures. This paper describes a brief introduction of the structure and results of a research program to develop a performance design system of building fire safety, organized by BRI under the financial support of Ministry of Construction. This program consists of the proposal of performance criteria of fire safety and development of prediction models of relevant phenomena. However, when a substitution of a specification code by a performance one is discussed for rationality, the equivalency of the new standard with the conventional one is an important problem to be clarified. Therefore, this paper will also discuss on the equivalency of the proposed system with the current regulations, and on the future scope of the application of this method to practical bullding design.

\section{BACKGROUND}

Present fire safety design for buildings in Japan is mostly dependent on the specification standards by Building Standard Law and Fire Service Law. Building designers consider often that fire prevention design would be just a blind observance of relevant standards for too small room for the design by architects. However, specification standards have been appreciated until recently for they enable designers, even amateurs in fire safety, to determine the fire safety measures easily. Relatively low 
population of qualified fire safety engineers may have been a positive reason for the survival of specification fire safety standards, while building standards in other areas such as structure and environment have turned to be based on performance. Also the present Building Standard Law is widely believed to provide relatively effective fire safety in buildings; all recent bullding fires resulting in considerable numbers of fatalities, i.e. more than 5, have taken place in those buildings as being significantly against Building Standard Law. The cause for fatalities in these fires have been very often attributed to the violation of the $1 \mathrm{aw}$. The fire statistics also show that the level of building fire safety in Japan is comparable or even better than in other industrialized countries. Articles of Building Standard Law related to fire safety have been revised often after large loss fires to prevent repetition of such loss. Such revision tends generally to enforce the requirements on fire safety, and its description is generally based on specification. However, recent advancement of building technology and growing interest in various building performances seem to have raised a number of drawbacks of this standard. Typical drawbacks are:

1) low efficiency or overlapping of fire safety measures

2) Low flexibility in architectural design

3) difficulty in the use of newly developed fire safety technologies

4) discouraging people to be interested in improving fire safety

5) difficulty in understanding actual level of fire safety

The first through third difficulties are mostly due to the typical manner of description of specification standards, which tends to be too specific and generally eliminate the concept of "trade-off". Typical difficulty of these categories appears when an engineer gives up to adopt some fire safety measure although he is sure that it is more reliable or more economical than the specification of the standard. Building Standard Law allows a building design against its general specification, if the design is approved by the Minister of Construction as equivalent with the safety requirement of the law. However, a difficulty arises again for the lack of the clear and definite description of the level of fire safety promised by Building Standard Law; long discussion on the equivalency has often preceded the approval and resulted eventually in the delay of the projects. The fourth and fifth problems are also related to the lack of definite description of the level of fire safety. Lack of a definite description of necessary performance is quite general in specification codes. It seems to be a main cause for people, especially for architects, to think that the safety would be equivalent to the law and to cease to think deeply about necessary safety level essentially required in the building with which they are concerned. All these circumstances further seem to discourage efforts to promote fire safety science. Therefore, the general criticism on the present fire safety regulation in Japan is not related to the level of safety it promises but on the nature of direct or indirect influences that it may cause.

BRI fire research group has felt strongly the necessity of performance fire safety standards and rational fire safety design for more than three decades, and many of BRI research activities on fire safety have aimed at establishing technical basis for the rational evaluation of fire safety in buildings. Recent progress in the scientific understanding of unwanted fires has brought a bright prospect to the development of rational fire safety evaluation method. As a trial to incorporate the progress in fire safety science to fire safety design, BRI organized a five-year research program to develop a performance design system for 
building fire safety in 1982 under the financial support and supervision of Ministry of Construction. The research budget for this program was approximately $\$ 50,000,000$ every year excluding salaries of the staffs of the Ministry including BRI; nearly half of the budget was consigned to two nonprofit organizations for the organizion of technical comittees consisting of more than 100 experts of fire research and engineering, architects etc.

\section{OUTLINE OF THE PROGRAM}

The research program was composed of two major subjects: one is the development of fire safety design method, and the other is related to the diagnosis of fire safety and renovation of existing buildings. This paper focuses on the former part for relatively subordinate role of the latter one as an application of the former to existing buildings. The development of the design system was basically pursued by three technical committees; the nature of the objective of each committee was assigned according to the difference of the nature of fire safety and relevant technical backgrounds.

Concept of Fire Safety of the Design Method

It should be noted that the purpose of this program is the development of a rational evaluation method of fire safety in buildings rather than the further improvement of fire safety. Since the appropriateness of the level of the fire safety promised by The Building Standard Law is widely agreed, it is desired to develop a rational design method equivalent to The Building Standard Law in terms of the safety level. Therefore, the analysis of the concepts of the present regulation was the subject of prior importance for starting the program. Since Building Standard Law describes only specifications of necessary fire safety measures, these concepts had to be "decoded" from specific articles of the law.

The most common purposes of fire safety design for buildings are:

1) prevention of fire outbreak due to an appropriate use of fire or heating apparatus

2) human safety in fire

3) prevention of public troubles

4) prevention of property losses

The "public troubles" mean any property loss or trouble generated as a result of fire at an owner or a tenant other than that of the place or building of fire outbreak. Typical examples of this category of fire loss are fire spread to other space or building, collapse of a high rise building, and an occurrence of city fire. Prevention of city fire has been recognized as one of the most important subject in the development of fire prevention technology during the modernization of Japan, since frequent occurrence of city fires during Edo era(1603-1867) brought tremendous loss and is even believed to have suppressed the industrialization. The frequent city fires have been mostly due to high density of wooden structures in traditional urban area. The fires in Tokyo at The Kanto Earthquake (1923) eventually resulted in more than 100 thousand fatalities.

Prevention of fire outbreak due to usual heating apparatus etc is the most primitive requirement for fire safety. Users of a building assume generally that appropriate use or slight but inevitable mishanding of 
fire or heating would not lead to an unwanted fire. Buildings should be protected against this kind of fire outbreak at least for realistic fire safety design and fire safety education to be effective. Human safety and prevention of public troubles are also recognized commonly as the most basic safety performance needed for a building, and their importance are mentioned directly or indirectly in some articles of the present Building Standard Law as in many conventional fire safety codes for buildings. The necessity of the prevention of property loss depends on the intension of the owner. Fire safety measures for this concept are not found in Building Standard Law, probably because of the voluntary nature of this concept. Moreover, while loss or damage of properties of public implication such as telecommunication may result in a significant public trouble, its prevention is very often beyond architectural fire safety measures.

In the development of the design system, prevention of fire outbreak by normal use of buildings, human safety and prevention of public troubles were taken as the basic fire safety for the equivalency to the Building Standard Law. However, it may be worth mentioning that the predictive methods and technical ideas for human safety and prevention of public troubles would still be applicable to the evaluation of property losses. Provision of necessary conditions for fire fighting and accessibility of a building by fire brigade were also taken as basic requirements, since fire fighting is compulsory and also expected to work as the trump for a situation where all fire safety measures cannot control a fire. Some detail of the adopted fire safety concepts is shown in Table 1.

Table 1 Fundamental Requirements for Fire Safety in Buildings

I. REQUIREMENTS AS AN INDIVISUAL BUILDING

1. Prevention of Outbreak and Rapid Propagation of Fire

2. Human Safety

2.1. Restriction of use of building materials exessively hazardous to evacuees

2.2. Adequacy of evacuation plan

2.3. Security of safety of refuges

2.4. Security of evacuation routes

3. Prevention of Serious Public Troubles

3.1. Prevention of fire spread to others' possession

3.2. Prevention of collapse or damage of building which causes serious troubles of others or public

4. Requirements for Fire Fighting Activities

4.1. Restriction of use of building materials excessively hazardous to fire fighting activities

4.2. Conditions for activities for searching and rescuing occupants

4.3. Conditions for activities for suppressing fire

\section{REOUREMENTS FOR CITY FIRE PREVENTION}

1. Buildings in Fire Protection Districts

2. Buildings in Quasi-fire Protection Districts 
However, it is human safety and prevention of public troubles that essentially needed performance standard. Therefore, the program concentrated mostly on human safety and prevention of public troubles.

\section{Evaluation Methodology}

Human safety and the prevention of public troubles are related to various fire safety science and technology. For the ease of technical studies and practical application of the design system, these concepts were shared by three subordinate design systems, prevention of fire out break and spread, smoke control and evacuation, and fire resistance. The nature and detail of these subordinate design systems are described in the next section; however, the structure of the evaluation methodology for each design system is quite similar.

Each subordinate design system is basically composed of the following components :

1) Fundamental requirements

2) Technical standards for engineering evaluation

3) Prediction method of relevant fire phenomena

4) Concepts of testing methods

The fundamental requirements are essentially the description of the basic fire safety concepts dealt with in each design system, including reasons for the necessity of each requirement, historic background of fire safety etc. This description is still too abstract for engineering evaluation. The fundamental requirements are translated into the "engineering quantitative language" with consideration of available tools of fire safety science and technology for engineering judgement based on predictive methods; these translated engineering criteria are the "technical standards". The technical standards are considered as subordinate to the fundamental requirements by its translated nature. In case that the technical standards do not seem to be effective to some new idea or invention of fire safety measure, its performance should be evaluated according to the fundamental requirements.

The technical standards provide criteria for the evaluation of fire safety by calculation, and are basically composed of the standard conditions of environment etc to be assumed for the calculation and the critical level in terms of engineering properties such as temperature, gas concentration etc. However, in actual design of relatively small buildings, a precise engineering prediction method may not result in such advantage as economy in construction or freer design compensating the elaborate study for the fire safety design. As a bypass for such situation, the technical standards sometimes provide specification requirements or different sets of critical level and standard conditions as far as possible(Figure 1); it was designed to bring a safer side design for specification requirements or rough estimation methods than for precise methods. Therefore a designer has eventually a choice between an easy study possibly resulting in rather restricted architectural design and an elaborate study for economical construction or for freer architectural design.

The "prediction method" is essentially the compilation of calculation models of related fire phenomena available for the engineering evaluation of fire safety. Its development was most elaborate in this program; however, the prediction method should not be regarded as a permanent 


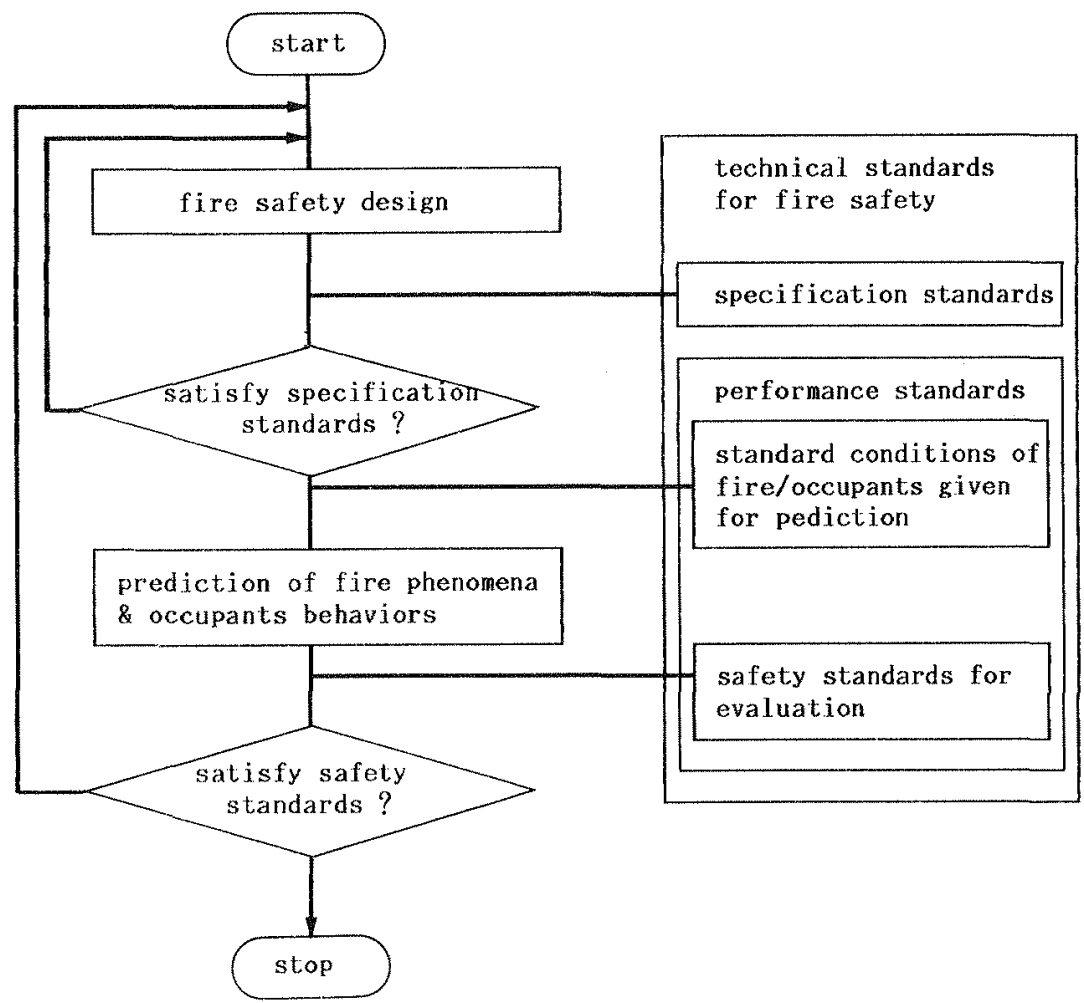

Figure 1 Relationship between Fire Safety Design and Technical Standards

standard, since many related fire phenomena are not understood sufficiently. From the nature of fire science as a basis for technology, there is always a room for the improvement of predictability of fire. If the prediction method were permanent, the system would rather discourage efforts to make the fire safety design more rational. The subjects of the proposed predictive methods are listed in Table 2.

The proposed prediction method is basicaliy a program to calculate evaluation indices for fire safety from such data as material properties and characteristics of building components. Testing method is necessary not only as a tool to quantify such data but also as a predictive method of such phenomena as being left to model in the present program. Several testing methods are proposed for this purpose(Table 3). However, some of these testing methods may still need refinement for practicality. Data base is provided for popular materials and building components as listed in Table 4.

Finally, the methodology of the proposed system is compared with the general evaluation methodology of Building Standard Law in Table 5. The general procedure of fire safety design based on this system is also illustrated in Figure 2. 
1. Combustion and fire behaviors

1.1 Ignition of conbustible materials

1.2 Behavior of turbulent diffusion flane

*1: Flame height

*2: Temperature and velocity on axis of turbulent diffusion flame and fire plume

*3: Amount of smoke included in turbulent diffusion flame and buoyant flow

*4: Radiative energy from turbulent diffusion flame

1.3 Formation of smoke layer and ventilation

1.4 Heat transmission at early stage of fire

*1: Spread of burning area at early stage of fire

*2: Radiative heat transfer to surroundings

*3: Convective heat transfer to ceiling, wall, floor, and other surfaces exposed to fire

1.5 Flame spread

*1: velocity of upper spread of flene on vertical surface

*2: velocity of steady-state spread of flame on surface with arbitrary heat flux distribution

*3: velocity of steady-state spread of flame on surface receiving constant heat flux

1.6 Effectiveness of automatic sprinkler

*1: respose time of fire extinction equipment

*2: time required for fire suppression

*3: properties of fire extinction equipment

1.7 Burning behavior at developed stage of fire

*1: standard fire temperature prescribed in the enforcement order of the Building Standard Law *2: nodels by Ingterg, Kawagoe, Magnusson, Babraskas, Harmathy etc.

1.8 Fire spread between buildings

*1: fire spread due to radiative heat transfer

*2: standardization of heat condition

*3: behavior of external flame

*4: behavior of flame rising up from a burning structure

2. Smoke movement and smoke control

2.1 single layer models

*1: steady-state model for nultiple compartments on multiple floors

*2: unsteady-state model for multiple compartments on multiple floors

2.2 two layer model

*1: unsteady-state model for single or multiple compartment on single floor

2.3 simplified model for evaluating smoke control systems

3. Evacuation behavior

3.1 model of evacuee ( properties, distribution, velocity of evacuees )

3.2 model of evacuation spaces or routes (room, path, stairs, hall, vestibule, link \& crowding )

3.3 model of evacuation behavior

*1: start time of evacuation

*2: evacuees' movement in an unit space

4. Fire resistance of building structure

4.1 fire temperature as heat load to the structure (which is given on the basis of the item 1.7 " buming behavior at developed stage of fire")

4.2 temperature of structural members

*1: model for reinforced concrete members (one /two dimensional heat flow)

*2: model for steel structural meabers

*3: model for assembled structural menbers ( for example; a structure assenbled by reinforced concrete slab and steel beari )

4.3 thernal stress and deformation

*1: model for reinforced concrete members

*2: model for steel structural wembers

*3: nodel for assembled structural members

5. fire safety performance of dwelling houses

5.1 evaluation model for evacuation safety in dvelling houses

*1: evaluation of difficulty for evacuation

5.2 evaluation model for performance of fire spread prevention 
1. Burning properties of funitures, building materials, components and equipments

1.1 Ignitability test

1.2 Flame spread test

1.3 Test of firemproof performance of building components against heat radiation

1.4 Toxicity test of combustion products from building materials

1.5 Measurement of combustion properties of furnitures

1.6 Measurement of combustion properties of materials

2. Properties for smoke-proof and smoke control

2.1 Test of flow resistance property of doors, windows and other openings and flow paths

2.2 Test of performance of smoke control equipinents

3. Fire resistance of building structures

3.1 Test of thermal properties of materials composing structures

3.2 Test of mechanical properties of materials composing structures

3.3 Fire resistance test of structural members

Table 4 Data Base for Fire Safety Design

1. Meteorological data

2. Live combustible load by building use

3. Thermal and combustible properties of building naterials

4. Mechanical properties of materials composing structures

5. Flow resistance properties of doors, windows, and other openings and flow paths

6. Number and density of occupants by building use

7. Hobility of evacuees by building use

Table 5 Relationship between Building Standard Law and The Proposed System

\begin{tabular}{|c|c|c|c|c|}
\hline & \multicolumn{2}{|c|}{ The Building Standard Law (BSL) } & \multicolumn{2}{|c|}{ The Fire Safety Design Systen } \\
\hline objectives & \multicolumn{2}{|c|}{$\begin{array}{l}\text { - life safety } \\
\text {-property protection } \\
\text {-public welfare }\end{array}$} & \multicolumn{2}{|l|}{$\begin{array}{l}\text { - life safety } \\
\text {-property protection } \\
\text {-public welfare }\end{array}$} \\
\hline $\begin{array}{l}\text { principle for } \\
\text { fire safety }\end{array}$ & \multicolumn{2}{|c|}{$\begin{array}{c}\text { Article } 35 \text { of BSL : security of } \\
\text { evacuation, fire fighting, activity }\end{array}$} & \multicolumn{2}{|c|}{$\begin{array}{l}\text { fundamental requirements } \\
\text { for fire safety }\end{array}$} \\
\hline $\begin{array}{l}\text { technical } \\
\text { standards }\end{array}$ & $\begin{array}{l}\text { associated orders } \\
\text { of BSL } \\
\text { (specification } \\
\text { standards) }\end{array}$ & $\begin{array}{l}\text { Article } 38 \text { of } \\
\text { BSL :article } \\
\text { for exception } \\
\text { (acceptance } \\
\text { of special } \\
\text { construction } \\
\text { methods etc) }\end{array}$ & $\begin{array}{l}\text { standard conditions } \\
\text { for prediction \& } \\
\text { safety standards } \\
\text { for evaluation } \\
\text { in terms of } \\
\text { performance and } \\
\text { specification }\end{array}$ & $\begin{array}{l}\text { special methods } \\
\text { of fire safety } \\
\text { evaluation } \\
\text { (based on } \\
\text { prediction for } \\
\text { special condi- } \\
\text { tions) }\end{array}$ \\
\hline $\begin{array}{l}\text { support } \\
\text { techniques }\end{array}$ & \multicolumn{2}{|l|}{ fire tests } & \multicolumn{2}{|c|}{$\begin{array}{l}\text { - calulation models (computer codes) } \\
\text { - fire tests -data base }\end{array}$} \\
\hline
\end{tabular}




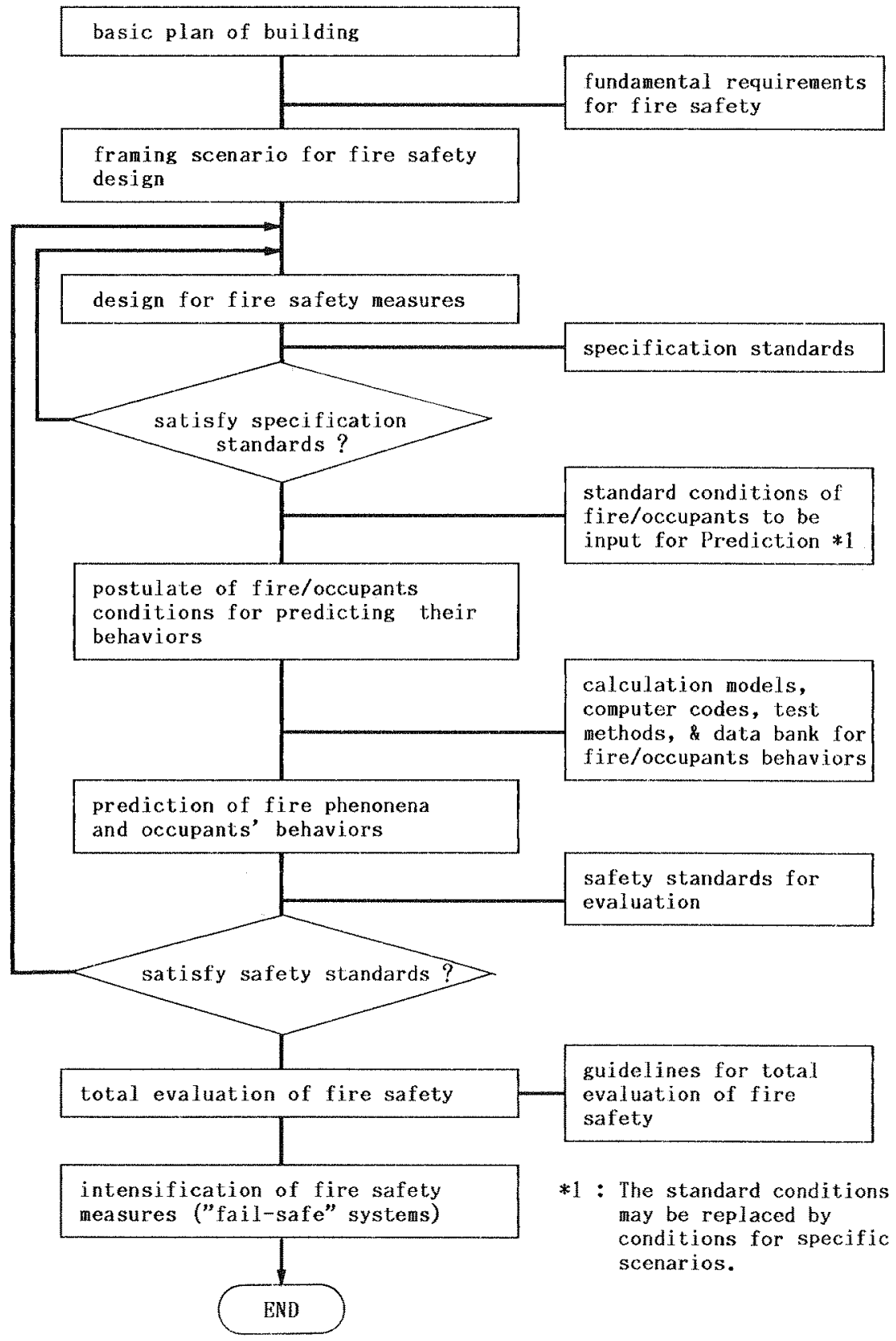

Figure 2 General Procedure of Fire Safety Design 
For the technical development related to human safety and prevention of public troubles, committees were organized on the following subjects:

1) Total fire safety

2) Prevention of fire outbreak and spread

3) Smoke control and evacuation

4) Fire resistance

5) Fire safety for dwellings

The division of these subjects, or committees except for total fire safety conmittee depends on the technical background for the related predictive methodologies, rather than on the ultimate fire safety performance. Fire modeling stands for the prevention of fire outbreak and spread, smoke movement and human behavior for the smoke control and evacuation, and structural engineering for fire resistance. Each of 2)-4) deals with some part of human safety and prevention of public troubles according to the affinity of the technical background to the fire safety performances, and proposed a component design system with the title of the committee as its name, e.g. design system for fire resistance from the fire resistance committee. Design procedure for respective subsystems are illustrated in Figure 3-5. It was designed that the total fire safety committee would string together the results of these committees to cover whole human safety and prevention of public troubles(Figure 6). The committee for the fire safety in dwellings was organized for the simplification of the evaluation method, since fire safety design using advanced scientific knowledge on fire does not seem to be practical for design of such small buildings as dwellings.

Human safety was shared by the committees for the prevention of fire outbreak and spread and for the smoke control and evacuation. Major causes for the generation of fatality in fire are smoke and the rapid growth of fire. Concentration or toxicity of smoke is the measure of human safety against smoke, while the development of flame to the ceiling or the appearance of flashover is the measure of prior importance in evaluating the human safety during early stages. Human safety during relatively early stages of a fire is dealt with mainly by the committee for the prevention of fire outbreak and spread, while life safety against smoke was studied by the committee for smoke control and evacuation.

Prevention of public troubles is basically a problem of a fully developed fire, and was shared by the comittees for the prevention of outbreak and spread of fire and for fire resistance. The committee for the prevention of outbreak and spread of fire mainly deals with the fire spread caused by fluiddynamic processes including external flames and stack effect. The committee for fire resistance deals with the prevention of the collapse or damage for structural members and the fire spread through structural members.

\section{FUTURE SCOPE AND APPLICATION}

The proposed design system needs relatively advanced knowledge on fire safety engineering, and it does not seem to take the place of the present standards soon. The new design system is supposed to be used for the fire safety design of such buildings as objects of the special approval by The Construction Minister for a while. Therefore, application 


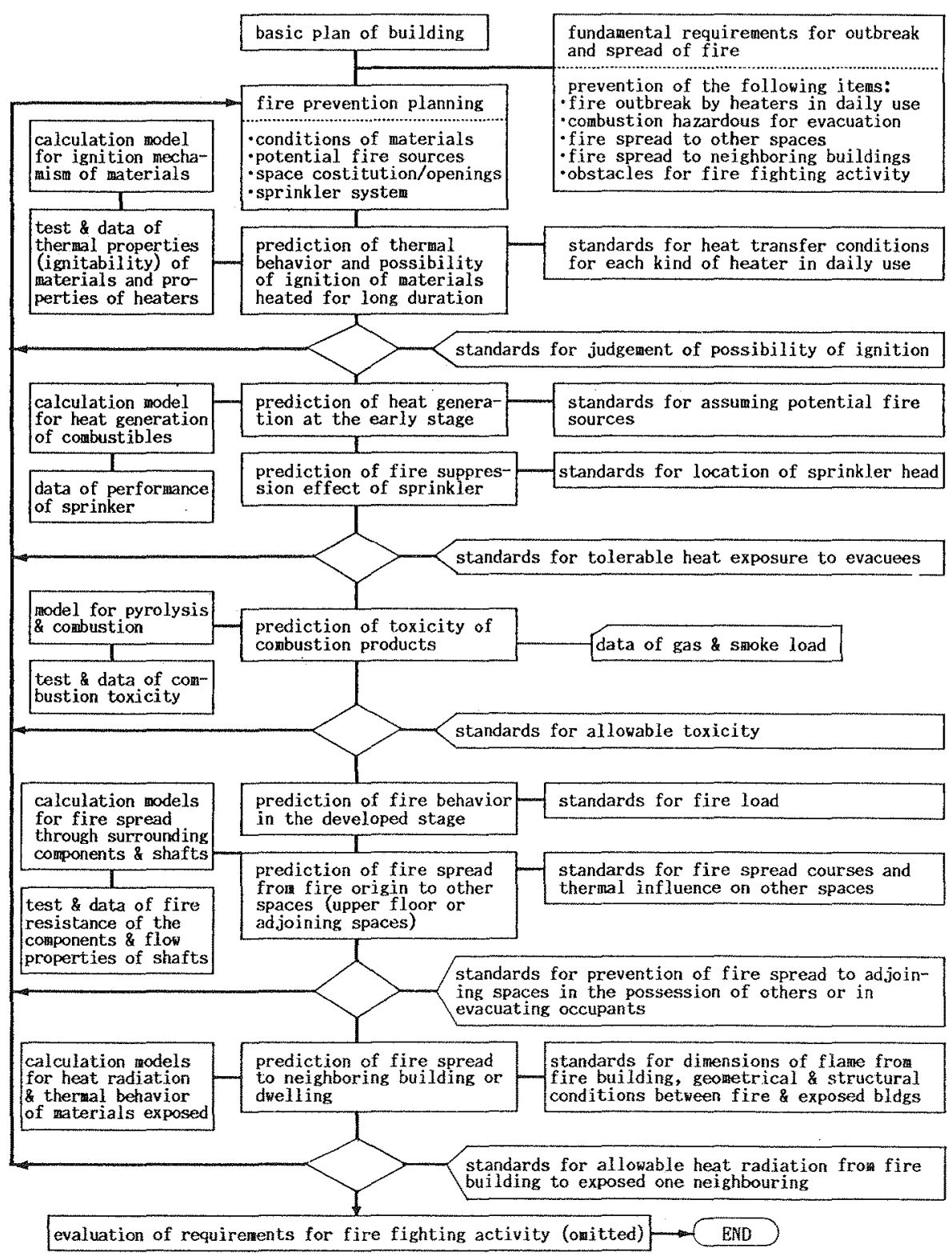

Figure 3 Evaluation and Design Procedure for Prevention of Fire Outbreak and Spread 


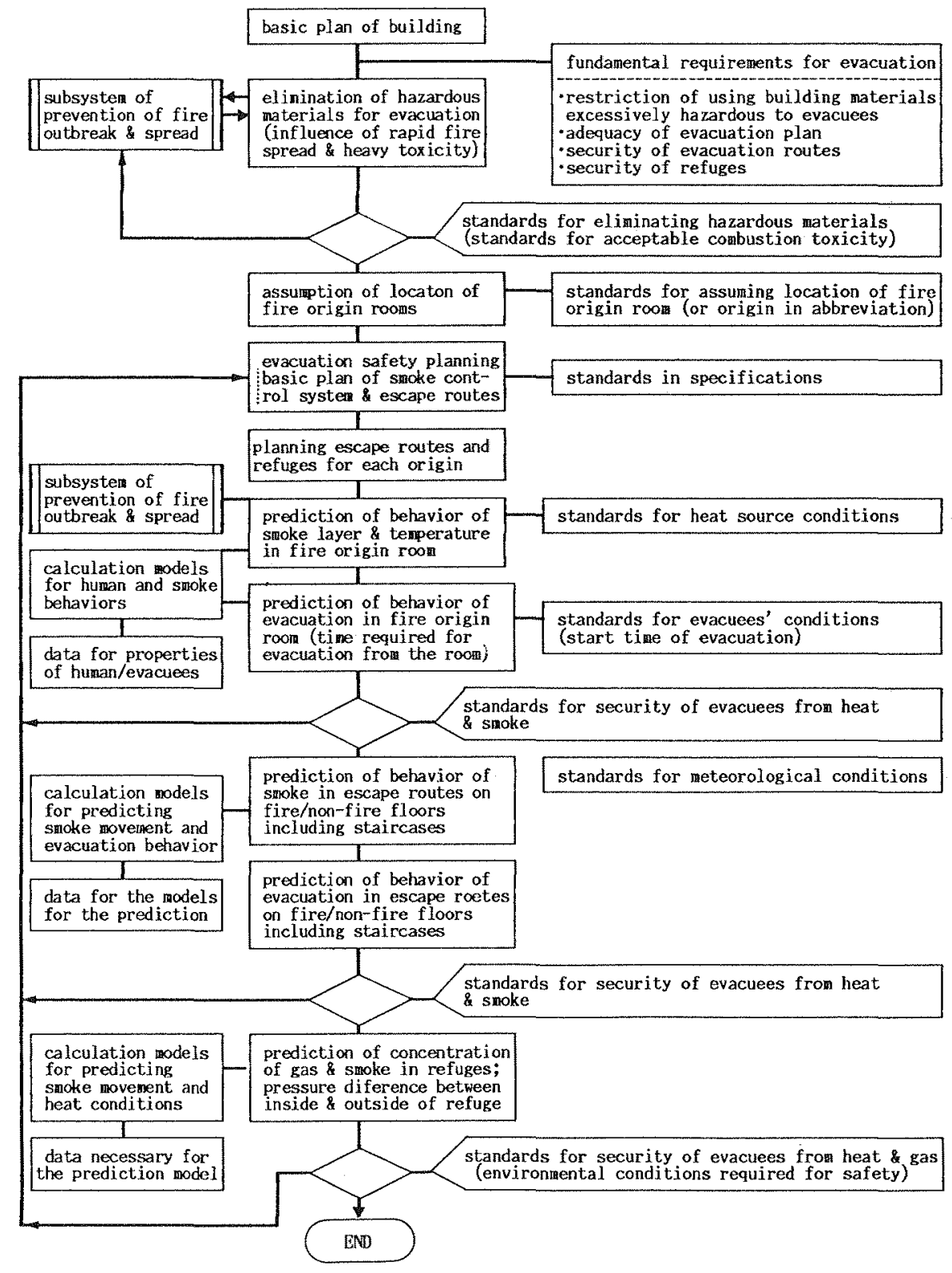

Figure 4 Evaluation and Design Procedure for Smoke Control and Evacuation 


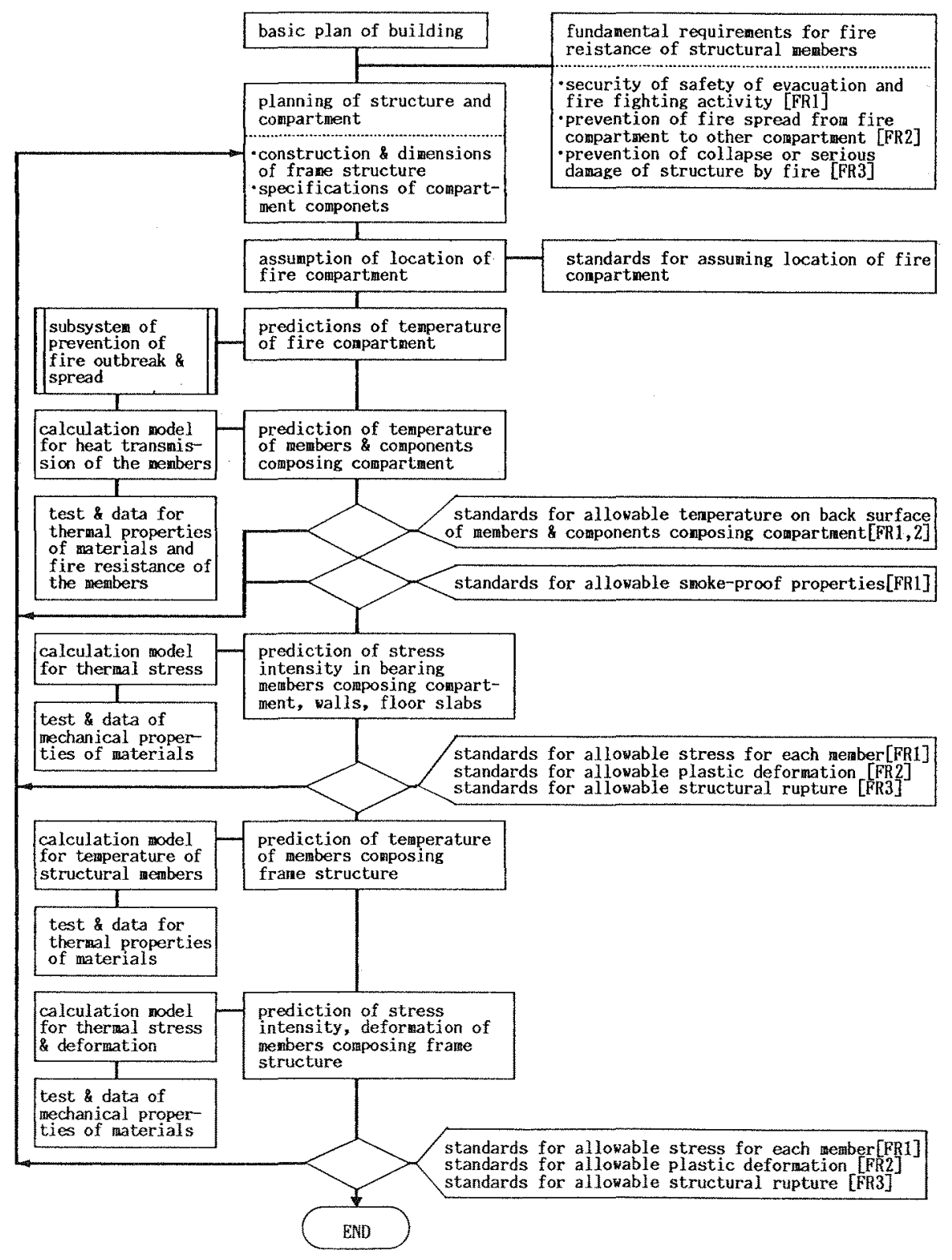

Figure 5 Evaluation and Design Procedure for Fire Resistance 


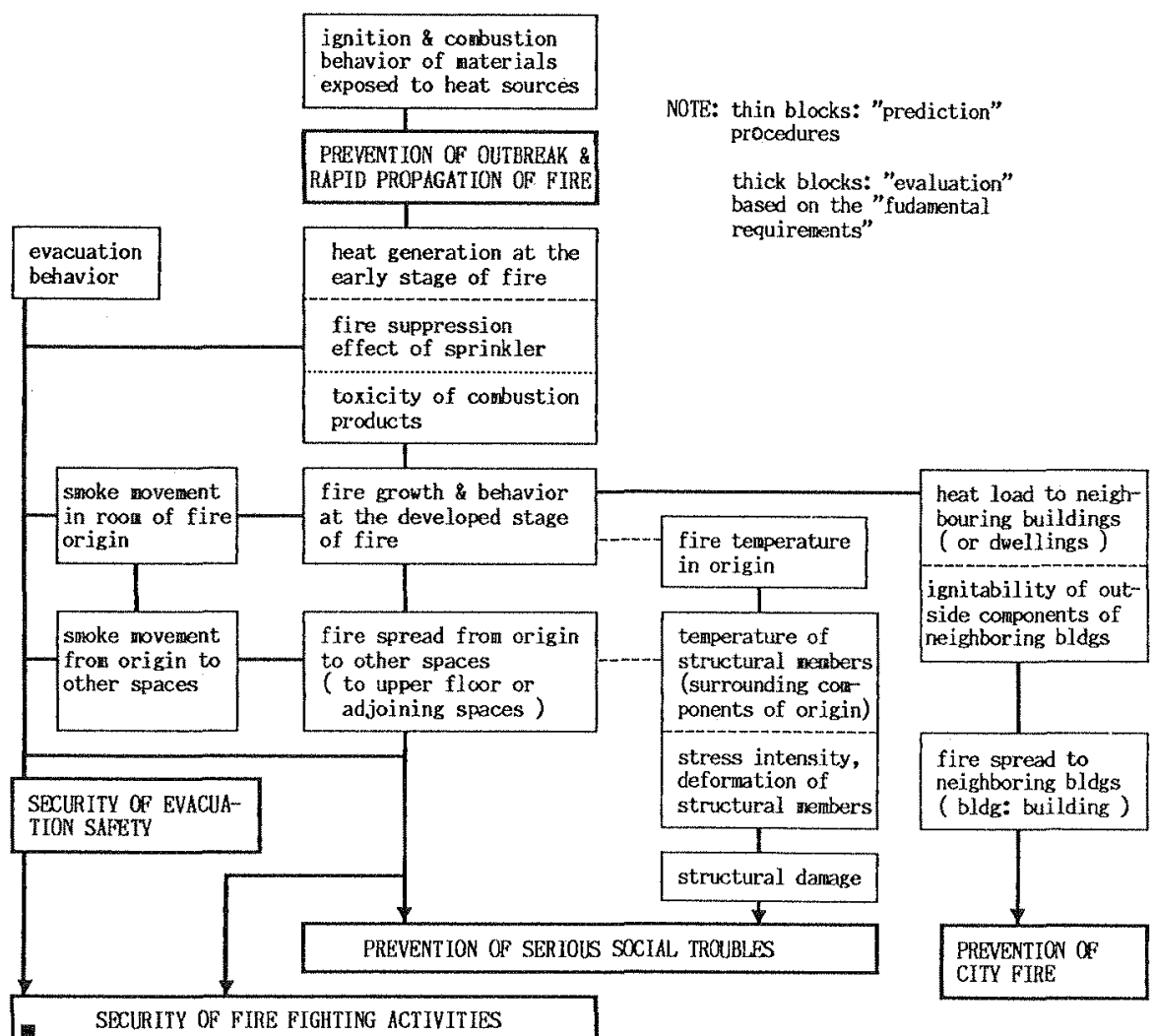

Figure 6 Scematic Diagram of Total Structure of Evaluation Procedure

of this design system may be still limited to relatively large or somewhat special construction projects. However, once the effectiveness of the new design system is recognized widely through its application examples, this system would gradually supersede the specification standards. In this sense, administrative promotion of the application of the new system is quite important for the diffusion of this system; The Ministry of Construction is framing an administrative system to authorize this design system as the technical background for this special approval.

The proposed design system has been actually applied to building design even during the process of its development. However, they are rather partial application of the predictive methods; its full application is being made on the design of the new national theater. Its basic design was determined by an international competition in 1986; this project of $56,000 \mathrm{~m}^{2}$ in total floor area stores three theaters, for ballet, opera, and contemporary performance arts respectively. The main interests of this project are the use of wood lining in the ballet and opera theaters and 
the stage spreadable to the seats according to the nature of play in the opera theater; all these are not allowed by the present Building Standard Law. The project is also against the fire safety standards for the use of a huge hall connecting the theaters and the entrance. Fire safety design for this project has been done under the guidance of BRI, and the study for this design includes computer simulation of smoke filling and evacuation, and relatively large scale tests on the flame spread along interior finishing materials. This case is expected to be an influencial example of the new design system.

When applying the new design system to actual buildings, it is sometimes felt that the conventional predictive methods are not effective to some realistic conditions and the available data base are not sufficient. While the recent progress of fire safety science is significant, we can predict fires only on limited and generally ideal situations. In order to promote the application of the new design system, it is important to improve predictive methods and to enrich the data base. Such improvement is partly going on through other research programs of Ministry of Construction on wooden structures and underground buildings.

\section{ACKNOWLEDGEMENTS}

The author presents this paper on behalf of the BRI Fire Research Group, since he was engaged in BRI and responsible for the research program by its end in 1987. The author would like to acknowledge the long term management of the program by the BRI Fire Research Group, and their assistance in the preparation of this paper. This paper is based on the report of the program for the final year(Ref.1). Ful1 report of this program for building engineers is to be published in 1988 .

\section{REFERENCES}

1. BRI: "Development of Design System for Building Fire Safety", Reports for 1986 Fiscal Year, Ministry of Construction, March, 1987 (in Japanese).

1. ballet theater

2. opera theater

3. sma11 theater
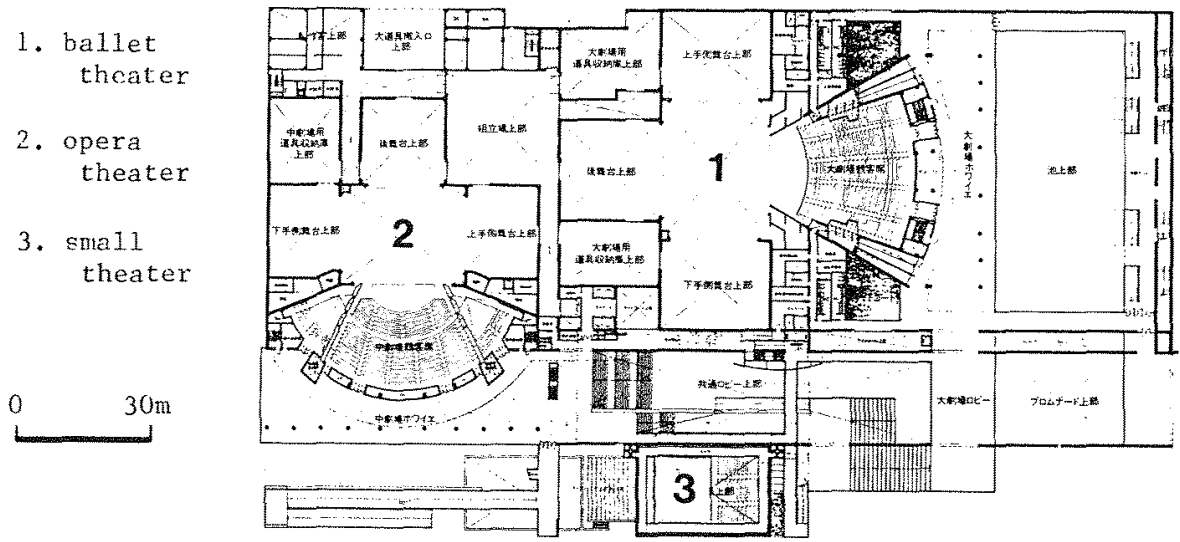

Figure 7 Main Floor Plan, New National Theater(Architect: T.Yanagisawa) The plan has been slightly changed from this competition plan. 
